\title{
Some Telling Examples: A Reply to Tsohatzidis*
}

RICHARD HOLTON

Lauri Karttunen (1978) and Zeno Vendler (1980) have independently claimed that tell behaves in two different ways, depending on its complement. When it is used with a whcomplement, as in

(1) The boy told them where he had spent the night

it requires that the subject spoke the truth: (1) could only be correctly used if the boy had spoken truthfully. In contrast, when tell is used with a that-complement, as in

(2) The boy told them that he had spent the night with friends

it brings no such requirement; (2) could be used correctly even if the boy had lied about his whereabouts.

In a recent paper Savas Tsohatzidis (1993) has disputed the first of these claims, that concerning the behaviour of tell with a wh-complement. He argues that Kartunnen and Vendler's account of this construction-which he dubs the $\mathrm{K}-\mathrm{V}$ thesis - is refuted by the following examples:

(3) John told the voters what he intended to do for them once elected, but, as usual, he was lying to them.

(4) Old John told us who he saw in the fog, but it turned out that he was mistaken.

(5) John told them where he had been between 4 and 5 p.m., but he was certainly lying since nobody was at the place he said during that time.

Tsohatzidis argues that each of these sentences (together with a number of others that he gives) is acceptable; yet each entails that the subject spoke falsely; so the $\mathrm{K}-\mathrm{V}$ thesis is false. $\mathrm{H}$ e goes on to explain the superficial plausibility of the $\mathrm{K}-\mathrm{V}$ thesis as the result of conventions of truthfulness and trust which, on David Lewis's (1975) account, are necessary for any language. These conventions guarantee that speakers will in general tell the truth, and that hearers will in general believe them. So we might expect that when people are reported as having been told something, there is a default assumption that they have been told the truth. According to Tsohatzidis it is the existence of such a default assumption-which can be defeated by explicit indication to the contrary as in (3), (4) and (5)-that makes the K-V thesis seem plausible.

If Tsohatzidis' argument were sound it would have important repercussions. For, as he points out, a considerable amount of work has been premised on the K-V thesis. H owever, I do not think that we should be convinced by his argument. In the first place, the explanation he gives for the plausibility of the K-V thesis appears to prove too much. If the general conventions of truthfulness and trust are enough to generate a default assumption that the subjects of tell+wh reports have spoken truly, they should equally generate a default assumption that the subjects of tell+that reports have likewise spoken truly. But there does not seem to be any such assumption; or at least it seems nothing like as strong as that governing tell +wh. There is far less reason to conclude from (2) than from (1) that the boy has spoken truly.

This should make us re-examine Tsohatzidis' counterexamples. When we do so, I think we will find that they do not make a convincing case for the falsity of the K-V thesis, since they are better explained in another way. Consider the following sentences: 
(6) He gave her a ring studded with diamonds, but they turned out to be glass.

(7) I saw a shooting star last night. I wished on it, but it was just a satellite.

(8) She knew that he would never let her down, but, like all the others, he did.

(9) He knew from experience that unless he made a formidable effort, a pattern was waiting to impose itself: a polite enquiry would elicit a polite response and another question ... H e had asked her about tea making. O ne more like that, and there would be nothing he could do ... Rather than tolerate more silence he settled after all for small talk, and began to ask, 'H ave you lived here long?' But all in a rush she spoke over him, saying, 'H ow do you look without your glasses? Show me please.'

These sentences do have a rather literary, melodramatic feel ((7) is from a Billy Bragg song; (9) is from I an M CE wan's novel The Innocent); but they are quite acceptable. However, it would be a rash theorist who argued from them to the conclusion that some diamonds are made of glass, that some shooting stars are satellites, and that know is not a factive. I suggest that these sentences work by projecting us into the point of view of the protagonist; let us call the phenomenon protagonist projection. In each case the point of view into which we are projected involves a false belief. We describe the false belief using words that the protagonists might use themselves, words that embody their mistake. So we deliberately use words in ways that do not fit the case. That is why they provide no evidence that some diamonds are made of glass, that some satellites are shooting stars and that knows is not a factive.

If this account of (6)-(9) is right, then in order to engage in protagonist projection we will need a protagonist on whom to project. When no such protagonist is available, we would expect the construction to become senseless. This is just what we find. Contrast the acceptable (10) with the bizarre (11):

(10) She sold him a pig in a bag. When he got home he discovered it was really a cat.

(11) ?T he wind blew a pig into the river. It was really a cat.

Now let us return to Tsohatzidis' argument. My contention is that his examples all involve protagonist projection. (3)-(5) have a similarly melodramatic feel to (6)(10). In each case we are being projected into the part of an audience who we can reasonably suppose did believe that the speaker was telling them the truth. In (3) this audience is the voters; in (4) it is 'us' before the discovery that Old John was mistaken (or perhaps it could be Old John himself); in (5) it is 'them'. Since these audiences believed that the speakers were telling the truth they would have reported them using tell+wh. But in using (3)-(5) we are not committed to thinking that tell twh is the proper construction to report those who falsely. We are simply projecting ourselves into the position of people who falsely believe them to be speaking truly, and from that position using a construction that we know to be in fact inappropriate. (3)-(5) thus no more undermine the $\mathrm{K}-\mathrm{V}$ thesis than (8) and (9) undermines the thesis that knows is a factive.

I have spoken of (3)-(5) as involving projection into the place of a audience who have false beliefs. But it might be objected that we do not require that the audience have false beliefs, as is shown by adapting another example of Tsohatzidis':

(12) John told us when he arrived in Paris, but we all knew that the time he gave us could not be correct: at that time he was still in Rome. 
I find (12) somewhat strained; but it is just acceptable. However, it can still be understood as involving protagonist projection. We do not in general need a protagonist who has actually been fooled. It is good enough to have someone who is simply a possible location for the salient false belief, especially if they are the target of a pretence. To see this consider these sentences, which are perhaps a little strained, but no more so than (12):

(13) She sold him a pig in a bag, but they both knew that it was really a cat.

(14) When they parted they exchanged photos and other keepsakes that would keep their love alive forever. But they both knew that it was hopeless.

(Compare too the related phenomenon, discussed by Donnellan (1966: 290-1) whereby we can use descriptions to refer to individuals even when none of us believes that they really denote them.)

In summary then, Tsohatzidis has given us no reason for rejecting the $\mathrm{K}-\mathrm{V}$ thesis. It remains eminently plausible.

\section{References}

Donnellan, Keith, 1966. Reference and Definite Descriptions. Philosophical Review 75: 281-304.

Karttunen, Lauri, 1978. Syntax and Semantics of Questions. In H H iz ed., Questions, 165-210. Dordrecht: Reidel.

Lewis, David, 1975. Languages and Language. Reprinted in his Philosophical Papers Vol. I, 163-88. Oxford: Oxford U niversity Press, 1983.

Tsohatzidis, Savas, 1993. Speaking of truth-telling: The view from wh-complements. Journal of Pragmatics 19: 271-79.

Vendler, Zeno, 1980. Telling the Facts. In J. Searle, F. Keifer, and M. Bierwisch eds., Speech Act Theory and Pragmatics, 273-90. Dordrecht: Reidel.

\section{Footnote}

* Thanks to Lloyd H umberstone and Rae Langton 